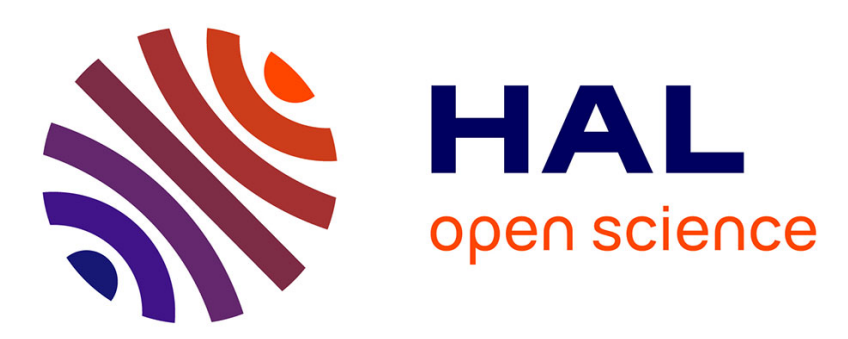

\title{
Inhibition of the carbachol-evoked synthesis of inositol phosphates by ototoxic drugs in the rat cochlea Sylvain Bartolami, Myriam Planche, Rémy Pujol
}

\section{To cite this version:}

Sylvain Bartolami, Myriam Planche, Rémy Pujol. Inhibition of the carbachol-evoked synthesis of inositol phosphates by ototoxic drugs in the rat cochlea. Hearing Research, 1993, 67, pp.203 - 210. hal-02163282

\section{HAL Id: hal-02163282 \\ https://hal.science/hal-02163282}

Submitted on 24 Jun 2019

HAL is a multi-disciplinary open access archive for the deposit and dissemination of scientific research documents, whether they are published or not. The documents may come from teaching and research institutions in France or abroad, or from public or private research centers.
L'archive ouverte pluridisciplinaire HAL, est destinée au dépôt et à la diffusion de documents scientifiques de niveau recherche, publiés ou non, émanant des établissements d'enseignement et de recherche français ou étrangers, des laboratoires publics ou privés. 


\title{
Inhibition of the carbachol-evoked synthesis of inositol phosphates by ototoxic drugs in the rat cochlea
}

\author{
Sylvain Bartolami, Myriam Planche and Rémy Pujol \\ INSERM U 254 and Université de Montpellier II, Laboratoire de Neurobiologie de l'Audition, Montpellier, France'
}

(Received 24 July 1992; Revision received 22 January 1993; Accepted 26 January 1993)

\begin{abstract}
The ability of amikacin, neomycin, ethacrynate, mercuric chloride and cisplatin to alter the inositol phosphate (IP) signalling pathway was assessed in the 12-day-old rat cochlea, where the turnover of IPs is coupled to muscarinic receptors. This study was motivated by: (1) the demonstration of neomycin binding to phosphatidylinositol 4,5-biphosphate, the precursor of IPs, and (2) the fact that ototoxic drugs induce some common symptoms in outer hair cells. At concentrations below $1 \mathrm{mM}$, none of the compounds changed the control ${ }^{3} \mathrm{H}-\mathrm{IP}$ formation. Mercuric chloride, cisplatin and ethacrynate inhibited the carbachol-induced formation of IPs in a dose-dependent manner with IC 50 values of 74,340 and $430 \mu \mathrm{M}$. respectively. The aminoglycosides were less efficient in reducing the carbachol-stimulated accumulation of IPs, since neither amikacin nor neomycin, both at $1 \mathrm{mM}$, had any significant effect. However, neonycin applied at 15 and $30 \mu \mathrm{M}$ induced $29 \%$ and $43 \%$ of inhibition of the stimulated IP response. Finally, additive effects are obtained between some of the toxic drugs. The results suggest that a block of the IP transduction system, associated with the cholinergic efferent innervation of the organ of Corti, is a feature that may be involved in some types of ototoxicity. The inefficiency of aminoglycosides and the putative targets of the ototoxic agents are discussed.
\end{abstract}

Aminoglycosides; Cisplatin; Ethacrynate; Mercuric chloride; Inositol phosphates; Cochlear muscarinic receptors

\section{Introduction}

In the mammalian cochlea, the noxious effects of ototoxic substances are known to occur preferentially at two levels: the stria vascularis and the organ of Corti (for reviews see: Hawkins, 1976; Rybak, 1986; Huang and Schacht, 1989). In the latter structure, the outer hair cells (OHCs) are the main targets of the various drugs, such as aminoglycosidic antibiotics (Forge, 1985; Lenoir and Puel, 1987; Richardson and Russell, 1991), mercurials (Falk et al., 1974; Thalmann et al., 1977; Anniko and Sarkady, 1978) and cisplatin (an anti-cancer drug; Nakai et al., 1982; Barron and Daigneault, 1987; Laurell and Bagger-Sjöbäck, 1991). All these substances, belonging to chemically unrelated groups, induce the degeneration of the OHCs. Their ototoxic actions are not, as yet, fully understood, and appear to be complex as revealed by the numerous effects induced by these molecules in the cochlea. Furthermore, the effects of the same class of drug can vary according to the stages of maturation, as indicated by the decrease in the toxic potency of the aminoglycosides

Correspondence 10: Sylvain Bartolami, INSERM U-254, Laboratoire de Neurobiologie de l'Audition, CHU St. Charles, 34059 Montpellier Cedex 1, France. Fax: (33) 6752-5601. observed during development (see for review Pujol, 1986).

In 1987, Williams and colleagues proposed a molecular model for the mechanism of aminoglycoside ototoxicity. One step of this model is the interaction between the aminoglycosides and polyphosphoinositides turnover (Orsulakova et al., 1976; Stockhorst and Schacht, 1977, Schacht, 1986) and this involves the binding of aminoglycosides to phosphatidylinositol 4,5biphosphate (PIP ${ }_{2}$; Lodhi et al., 1976; Schacht, 1979, 1986), the precursor of the second messengers inositol trisphosphates and diacylglycerol (Berridge and Irvine, 1984; Nishizuka, 1984). Aminoglycoside binding reduces the $\mathrm{PIP}_{2}$ hydrolysis and would disturb the synthesis of IPs within the cochlea. In this organ, the IP signalling pathway may be associated with the motility of the OHCs (Schacht and Zenner, 1987) and has been demonstrated to be coupled to muscarinic acctylcholine receptors (Guiramand et al., 1990b; Niedzielski et al., 1992), which are probably of the M3 subtype (Guiramand et al., 1990b). Moreover, activation of these receptors results in an enhanced synthesis of IPs during the second and third weeks of post-natal development in the rat, 'with a peak of enhanced activity being found at post-natal day 12 (Bartolami et al., 1990). This peak is concomitant with both the occur- 
rence of plastic events leading to efferent synaptogenesis at the OHC level (Lenoir et al., 1980; Simmons et al., 1990; Cole and Robertson, 1992) and the period of increased susceptibility of OHCs to aminoglycoside-induced toxicity (see for review, Pujol, 1986).

In view of the interaction between the aminoglycosides and $\mathrm{PIP}_{2}$ hydrolysis, that is associated with the cholinergic efferent system innervating the organ of Corti (Altschuler et al., 1985; Eybalin and Pujol, 1987; Dannhof et al., 1991), it is conceivable that a blockage of the IP transduction system could be a common factor underlying drug-induced ototoxicity. This proposal is also supported by the fact that the various ototoxic molecules induced some common molecular symptoms. For instance, the mechano-transduction channels of the frog vestibular hair cells are blocked by the aminoglycosides (Kroese et al., 1989), as are those of hair cells in the mouse organ of Corti (Richardson et al., 1989; Kössl et al., 1990), and cisplatin has a similar effect (McAlpine and Johnstone, 1990). Furthermore, aminoglycosides and cisplatin both suppress calcium influx into isolated OHCs, via voltage-gated calcium channels (Dulon et al., 1989; Saito et al., 1991). Physiologically, ototoxic damage to the OHCs can be monitored by the inhibition of the cochlear microphonic. Such inhibition occurs following the application of aminoglycosides (Nuttall et al., 1977; Konishi, 1979; Takada and Schacht, 1982), cisplatin (Konishi et al., 1983) and mercurials (Thalmann et al., 1977; Konishi and Hamrick, 1979). Finally, other ototoxic molecules, the 'loop diuretics', can enhance the damage induced by aminoglycosides (Russell et al., 1979; Hayashida et al., 1989) and cisplatin (Laurell and Engström, 1989; McAlpine and Johnstone, 1990).

In order to assess the hypothesis that otoxic molecule other than aminoglycoside can interfere with the metabolism of IPs, we investigated the effects of five ototoxic molecules cisplatin, mercuric chloride, ethacrynate (a 'loop' diuretic), amikacin and neomycin (two aminoglycosides) on the synthesis of IPs that is stimulated by carbachol, a muscarinic preferring agonist, in 12-day-old rat cochleas.

\section{Materials and Methods}

\section{Reagents}

Myo- $\left[2-\left({ }^{3} \mathrm{H}\right)\right]$-inositol (specific activity: $17.02 \mathrm{Ci}$ per mmol) was purchased from Dositek (France) and trypsin from Gibco. Carbachol, amikacin sulphate, neomycin sulphate, ethacrynate, cisplatin (cis-diamminedichloro platinum II) were obtained from Sigma. All other compounds were of analytical grade.

\section{Dissection of the cochleas}

Twelve-day-old Wistar rats were killed by quick cervical transection. The cochleas were rapidly dis- sected and collected in Krebs-Ringer buffer (concentration in $\mu \mathrm{M}: 125 \mathrm{NaCl}, 3.5 \mathrm{KCl}, 1.25 \mathrm{KH}_{2} \mathrm{PO}_{4}$, $1.2 \mathrm{MgSO}_{4}, 1.5 \mathrm{CaCl}_{2}, 25 \mathrm{NaHCO}_{3}$ and 10 glucose). Throughout the experiment, the cochleas were maintained in the Krebs-Ringer buffer, which was equilibrated to $\mathrm{pH} 7.4$ by saturation with a gaseous mixture of $95 \% \quad \mathrm{O}_{2}$ and $5 \% \quad \mathrm{CO}_{2}(\mathrm{vol} / \mathrm{vol})$. The dissected cochleas are composed of the organ of Corti, the spiral ganglion and the modiolus. These three parts were not used separately, but are a single unit of tissue.

\section{Labelling of the cochlear tissues}

${ }^{3} \mathrm{H}$-inositol incorporation into the cochleas was carried out at $37^{\circ} \mathrm{C}$, for $75 \mathrm{~min}$ in Krebs-Ringer buffer containing $1 \mu \mathrm{M}$ cytidine and $10.8 \mu \mathrm{Ci} / \mathrm{ml}$ of myo-[2${ }^{3} \mathrm{H}$ ]-inositol. Labelling of the cochleas was achieved by using $89 \mu \mathrm{l}$ of radioactive Krebs-Ringer buffer per cochlea. The cochleas were washed four times with Krebs-Ringer buffer and then individually distributed in plastic test tubes containing $500 \mu \mathrm{l}$ Krebs-Ringer buffer. The tubes were quickly transferred to a water bath with the temperature set at $37^{\circ} \mathrm{C}$ and continuously bubbled with the $95 \% \mathrm{O}_{2} / 5 \% \mathrm{CO}_{2}$ mixture.

Stimulation synthesis of IPs and extraction of the tritiated IPs

The toxic agents (where applicable) and $\mathrm{LiCl}(10$ $\mathrm{mM}$ ) that blocks the IP cycle and therefore results in the accumulation of IPs (Berridge ct al., 1982) were added to each tube, $15 \mathrm{~min}$ prior to stimulation by carbachol $(1 \mathrm{mM})$. The muscarinic agonist was allowed to react for $20 \mathrm{~min}$. The reaction was stopped by the application of $50 \mu \mathrm{l}$ of perchloric acid $(72 \%)$ per tube and by placing the tubes on ice. The cochleas were homogenised by sonication and the homogenates were centrifuged at $2000 \times g$ for $5 \mathrm{~min}$. The supernatants containing the ${ }^{3} \mathrm{H}$-IPs were neutralised with $1.5 \mathrm{M}$ $\mathrm{KOH} / 0.075 \mathrm{M}$ HEPES. After separation from ${ }^{3} \mathrm{H}$-inositol and glycerophosphoinositols by anion-exchange chromatography, the ${ }^{3} \mathrm{H}$-IPs formed were measured in each cochlea as described previously (Guiramand et al., 1990b).

\section{Assessment of cell death}

Cochleas that had been stimulated by $1 \mathrm{mM}$ carbachol (control) and cochleas that had been stimulated by $1 \mathrm{mM}$ carbachol after pre-treatment with either ethacrynate $(1 \mathrm{mM})$ or cisplatin $(1 \mathrm{mM})$ were taken at the end of the experiment (before the addition of the perchloric acid) and rinsed in Krebs-Ringer buffer. The organs of Corti were dissected and exposed to $0.25 \%$ trypsin for $30 \mathrm{~min}$ at room temperature. Then they were washed in Krebs-Ringer buffer and mechanically dissociated with a Pasteur pipette. Trypan blue $(0.04 \%)$ was added to each sample. The blue-stained dead cells and the unstained living cells were counted using a Malassez device. 


\section{Data expression and statistical analysis}

The data are expressed as either percentages of the maximum level of accumulation of IPs induced by carbachol $(1 \mathrm{mM})$ or percentages of the control, basal level of synthesis of IPs. This basal level is expressed as the ratios of the ${ }^{3} \mathrm{H}$-IPs (in dpm) accumulated to the amounts of $\mathrm{dpm}$ of ${ }^{3} \mathrm{H}$-inositol taken up per cochlea (dpm ${ }^{3} \mathrm{H}$-IPs / dpm ${ }^{3} \mathrm{H}$-inositol). The amounts of $\mathrm{dpm}$ of ${ }^{3} \mathrm{H}$-inositol taken up per cochlea is measured in the flow-through fraction of the anion exchanged chromatography, as described clsewhere (Guiramand et al., $1990 \mathrm{~b}$ ). All the data points are means \pm SEM of 6 experiments, at least. The statistical significance of the data was determined using a two-tailed Student's $t$-test.

\section{Results}

In non stimulated cochleas, the basal level of synthesis of IPs is $0.072 \pm 0.005( \pm$ SEM $)$ dpm ${ }^{3} \mathrm{H}-$ IPs $/ \mathrm{dpm}{ }^{3} \mathrm{H}$-inositol, the addition of carbachol (1 mM) raises the IP response to $0.336 \pm 0.036 \mathrm{dpm}{ }^{3} \mathrm{H}$ IPs $/ \mathrm{dpm}{ }^{3} \mathrm{H}$-inositol. This rise correspond to an increase of $461 \pm 51 \%$ of the basal level. The application of mercuric chloride (Fig. 1), ethacrynate (Fig. 2) and cisplatin (Fig. 3) results in dose-dependent inhibition of the synthesis of IPs induced by carbachol $(1 \mathrm{mM})$ in the 12-day-old rat cochlea. The $\mathrm{IC}_{50}$ values of $74 \mu \mathrm{M}$, $0.34 \mathrm{mM}$ and $0.43 \mathrm{mM}$ are obtained for mercuric chloride, cisplatin and ethacrynate, respectively. This suggests the following relative order of efficacy: mercuric chloride $>$ cisplatin $>$ ethacrynate. The inhibitions evoked by ethacrynate and cisplatin are very sharp, as indicated by the steep slopes of the dose-re-

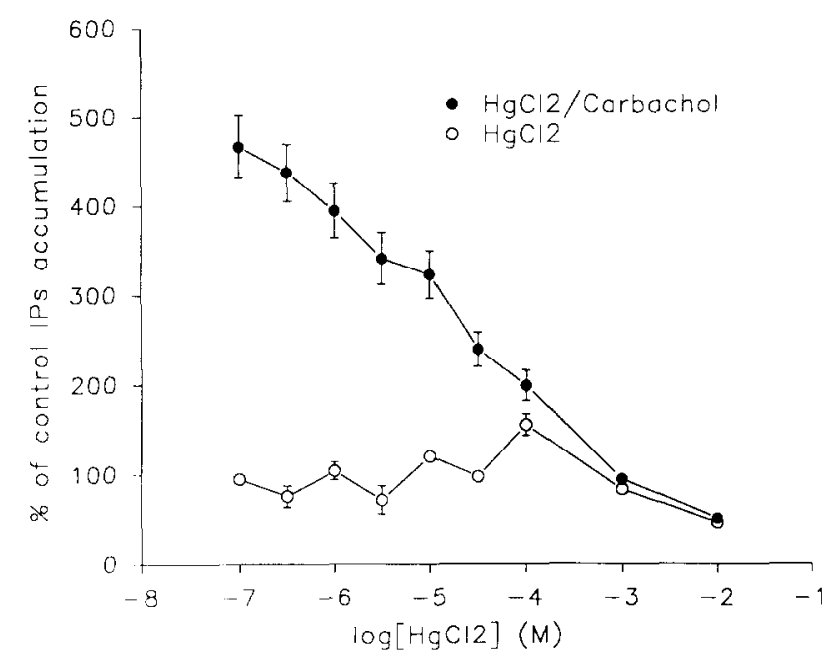

Fig. 1. Dose-response curve of the inhibition of the carbachol-induced formation of IPs by mercuric chloride.. The data are means \pm SEM of 6 individual measurements, at least, and are expressed as percentages of the basal formation of IPs that is $0.072 \pm 0.005 \mathrm{dpm}$ ${ }^{3} \mathrm{H}$-IPs $/ \mathrm{dpm}^{3} \mathrm{H}$-inositol. When error bars are not indicated, the width of the bars is smaller than the thickness of the symbols.

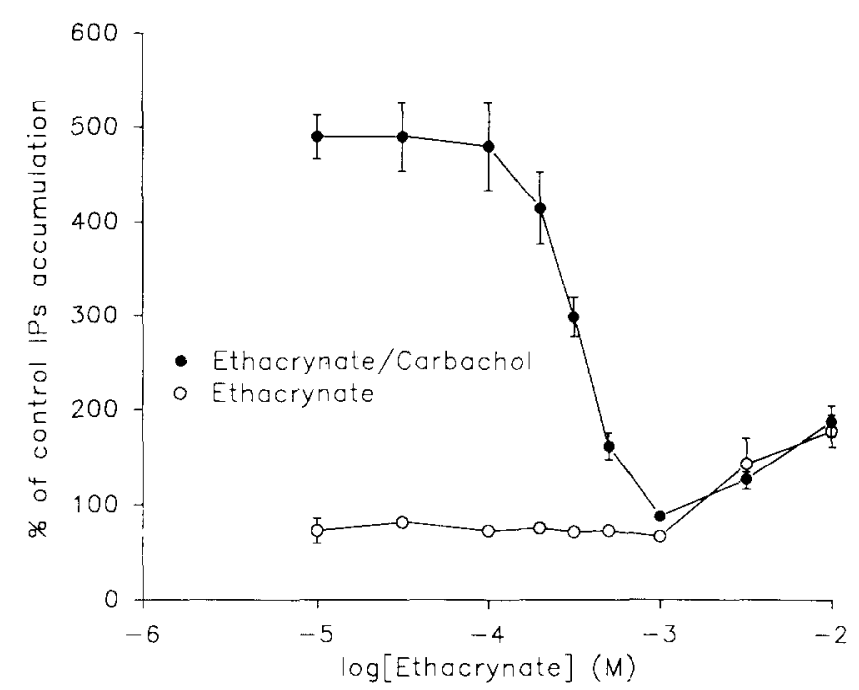

Fig. 2. Dose-response curve of the inhibition of the carbachol-induced formation of IPs by ethacrynate. The data are means \pm SEM of 6 individual measurements, at least, and are expressed as percentages of the basal formation of IPs that is the same as in Fig. 1. When error bars are not indicated, the width of the bars is smaller than the thickness of the symbols.

sponse curves (Figs. 2 and 3), whereas the effect of mercuric chloride upon the stimulated IPs synthesis extends over $4 \log$ units (Fig. 1).

The maximum reductions in carbachol-enhanced formation of IPs are obtained with mercuric chloride at a concentration of $1 \mathrm{mM}$, ethacrynate at $1 \mathrm{mM}$ and cisplatin at $0.4 \mathrm{mM}$. At these concentrations, the levels of formation of IPs obtained in the presence of carbachol are $0.068 \pm 0.005,0.063 \pm 0.005$ and $0.145 \pm 0.015$ $\mathrm{dpm}{ }^{3} \mathrm{H}$-IPs $/ \mathrm{dpm}{ }^{3} \mathrm{H}$-inositol for mercuric chloride,

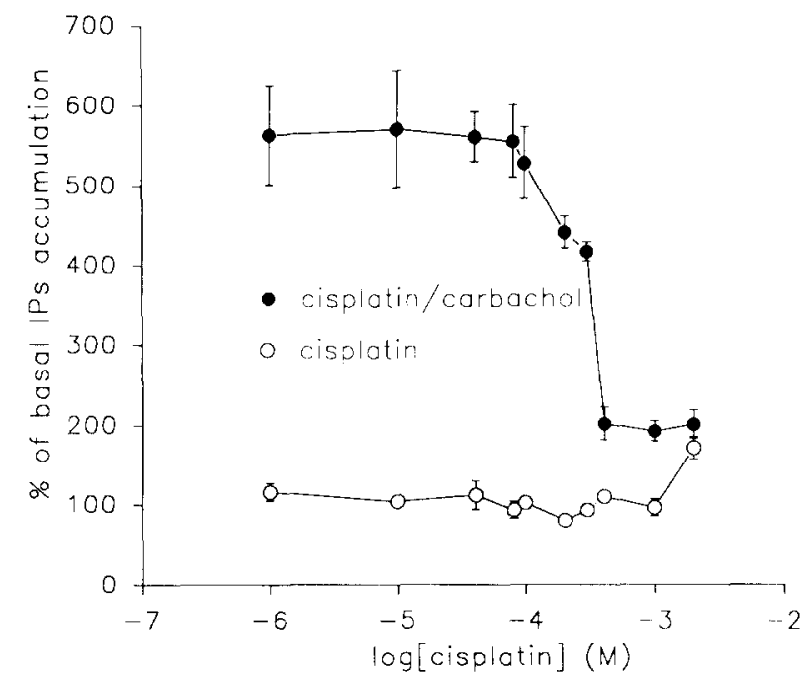

Fig. 3. Dose-response curve of the inhibition of the carbachol-induced formation of IPs by cisplatin. The data are means \pm SEM of 6 individual measurements, at least, and are expressed as percentages of the hasal formation of IPs that is the same as in Fig. 1. When error bars are not indicated, the width of the bars is smaller than the thickness of the symbols. 
ethacrynate and cisplatin, respectively. The measured responses do not extend above the control basal level in the cases of mercuric chloride $(1 \mathrm{mM}$, Fig. 1) and ethacrynate ( $1 \mathrm{mM}$, Fig. 2). Both compounds behave therefore as full antagonist while cisplatin is a partial antagonist.

In the absence of carbachol, mercuric chloride, at 10 $\mathrm{mM}$, reduces the synthesis of IPs by $54 \%$ (Fig. 1). On the other hand, ethacrynate and cisplatin, at concentrations higher than $1 \mathrm{mM}$, significantly enhance the level of synthesis of IPs (Figs. 2 and 3), with levels of accumulation of IPs rising by $71 \%$ and $78 \%$ when cisplatin $(2 \mathrm{mM})$ and ethacrynate $(10 \mathrm{mM})$ are applied in the absence of carbachol (in both cases, $P<0.001$ ). Due to the high concentrations of toxins that promote these changes of the non stimulated IP synthesis, these modifications have little pharmacological significance.

The two aminoglycosides amikacin and neomycin were less efficient in changing the levels of basal or carbachol-stimulated synthesis of IPs than the other compounds. Indeed, the application of amikacin (1 $\mathrm{mM}$ ) and neomycin (1, 15 and $30 \mathrm{mM}$ ) do not alter the basal level of synthesis of IPs (data not shown). When the metabolism of IPs is subjected to muscarinic stimulation (carbachol, $1 \mathrm{mM}$ ), amikacin and neomycin, at 1 $\mathrm{mM}$, do not show any significant inhibitory effects (Fig. 4). However, neomycin, at higher concentrations (15 and $30 \mathrm{mM}$ ), is able to partially block the carbacholstimulated synthesis of IPs (Fig. 4). At these concentrations, neomycin provokes, respectively, $29 \%$ and $43 \%$ inhibitions of the carbachol-elicited accumulation of IPs $(P<0.01)$. Experiments, using aminoglycoside at

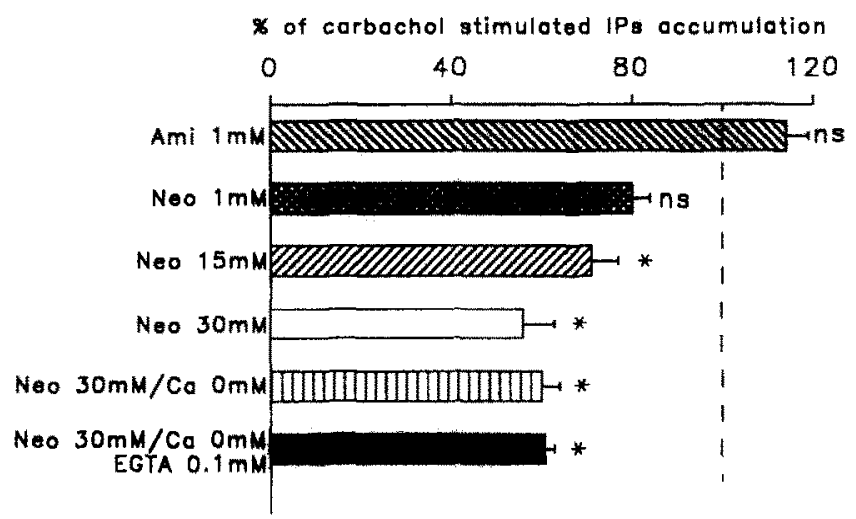

Fig. 4. Effects of amikacin sulphate and neomycin sulphate on the carbachol-evoked accumulation of IPs. The effects of neomycin ( 30 $\mathrm{mM}$ ) were assessed both in normal medium and in calcium-free medium (the two lower bars). The formation of IPs per cochlea is expressed as a percentage of the mean, maximum accumulation of IPs provoked by carbachol $1 \mathrm{mM}$. This maximum level of accumulation of IPs is taken as $100 \%$. Dash line indicates the $100 \%$ level that corresponds to $467 \pm 51 \%( \pm \mathrm{SEM})$ of the mean basal synthesis of IPS indicated in Fig. 1. Error bars are SEM of, at least, 6 measurements. Ami: amikacin sulphate, neo: neomycin sulphate, ca: calcium, ns: non significantly different from the $100 \%$ level, *: significantly different from the $100 \%$ level with $P<0.01$.

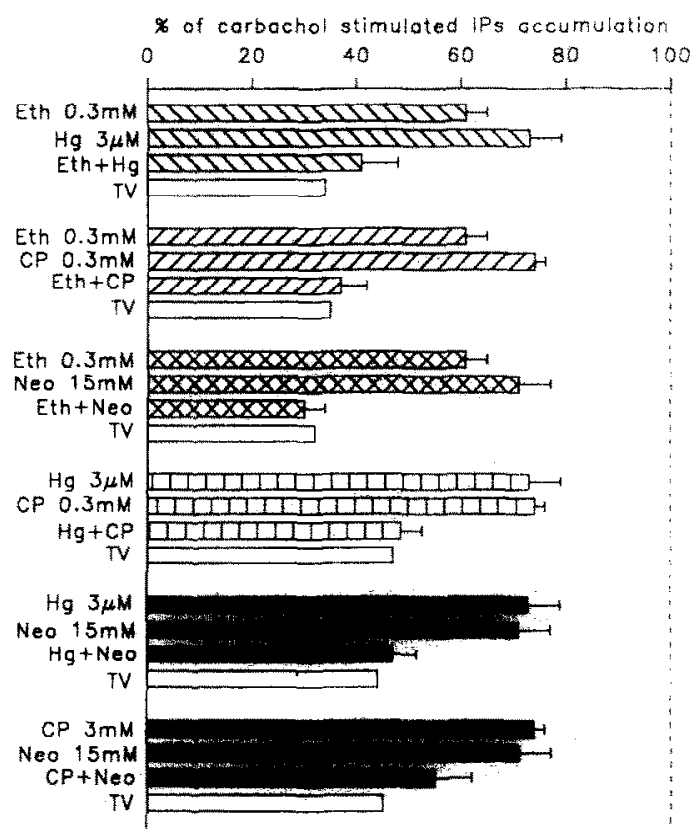

Fig. 5. Effects of combined-drugs exposures on the carbachol-elicited synthesis of IPs. The drugs were used at concentrations close to their respective $\mathrm{IC}_{30}$ (except for neomycin). Data are means \pm SEM of at least, 6 individual determinations and are expressed as indicated in Fig. 4. For every combination, the inhibitions of the IP response, induced by each member of the pair are given as well as the theoretical value of additivity calculated from these individual levels of inhibition. All experimental data are statistically different from the $100 \%$ level (dash line) with $P<0.01$. Eth: ethacrynate, $\mathrm{Hg}$ : mercuric chloride, $C P$ : cisplatin, Neo: neomycin, TV: theoretical value of additivity

high concentrations, were conducted only with neomycin, for it is the most toxic antibiotic, in term of interaction with the turnover of IPs, while amikacin is one of the least active (Wang et al., 1984; Schacht, 1986). Since calcium and aminoglycosides compete to interact with the plasma membrane (Takada and Schacht, 1982), attempts to increase the neomycinelicited blockage of the stimulated IPs response included omitting calcium from the reaction medium and the addition EGTA $(0.1 \mathrm{mM})$ to the calcium free reaction medium. In both conditions, no increase in the rate of inhibition is seen (Fig. 4).

Tests of additivity of the effects of the otoxic substances were achieved by using these drugs at concentrations smaller than their respective $\mathrm{IC}_{50}$ (except for neomycin). The results were compared to the theoretical values of additivity. These theoretical values were calculated by subtracting, from the $100 \%$ level, the sums of the individual levels of inhibition provoked by each individual drug, when applied on its own. The effects were additive with the following combinations: ethacrynate $0.3 \mathrm{mM} /$ cisplatin $0.3 \mathrm{mM}$, ethacrynate 0.3 $\mathrm{mM} /$ neomycin $15 \mathrm{mM}, \mathrm{HgCl}_{2} 3 \mu \mathrm{M} /$ cisplatin $0.3 \mu \mathrm{M}$ and $\mathrm{HgCl}_{2} 3 \mu \mathrm{M} /$ neomycin $15 \mu \mathrm{M}(P<0.01$, Fig. 5) with the differences between the theoretical values of 
additivity and the experimental data obtained when using those drug associations being smaller than the SEM of the experimental data. With the drug combinations ethacrynate $0.3 \mathrm{mM} / \mathrm{HgCl}_{2} 3 \mu \mathrm{M}$ and cisplatin 3 $\mathrm{mM} /$ neomycin $15 \mu \mathrm{M}$ the inhibitions of the carbachol-enhanced formation of IPs is less than theoretical values of additivity (Fig. 5).

In comparison to control, the amount of cell death in organs of Corti exposed either to cisplatin (1 mM) or to ethacrynate $(1 \mathrm{mM})$ is not significantly different. Indeed, in untreated organs cell death is $46 \pm 18 \%$ while it amounts to $47 \pm 12 \%$ and $43 \pm 19 \%( \pm$ SEM, in all case $N=3$ ) in organs of Corti exposed to cisplatin and ethacrynate, respectively.

\section{Discussion}

We have previously shown that the muscarinic stimulation of the IP synthesis is maximum in the 12-day-old rat cochlea (Bartolami et al. 1990). At this age, the OHCs are particularly sensitive to aminoglycoside ototoxicity (Pujul, 1986). Therefore we chose this developmental stage for the present study.

Our data demonstrate the inhibitory effects of ototoxic agents on the synthesis of the IP second messengers stimulated by a muscarinic agonist, in the 12-dayold rat cochlea. Similar suppressive actions by ototoxic drugs on carbachol-induced IP metabolism, in 8-day-old rat brain synaptoneurosomes (Guiramand et al., 1990a), reinforce our present findings. These authors suggested that the blockage of the agonist-activated turnover of IPs is likely to be due to a disturbance in the transduction system itself, rather than to a direct effect of the various ototoxic molecules on the brain muscarinic receptors. However, the results obtained here with the rat cochlea cannot provide any direct evidence for this hypothesis. The fact that the drugs only inhibit the carbachol-stimulated formation of IPs, and not the basal turnover of IPs at concentration of drugs below $1 \mathrm{mM}$, suggests that the cochlear muscarinic receptors may be sensitive to the toxic agents. Also, one should point out that the molecular nature of the proteins involved in the signalling pathway may differ from the brain to the cochlea.

Concerning ethacrynate and cisplatin, one could argue that their inhibitory activity may be due to their cytotoxic properties. However this does not seem to be the case, firstly because cisplatin does not affect the viability of OHCs in vitro (Saito et al., 1991), and secondly in view of our results of the assessment of the overall cell survival in the organ of Corti. However, since the number of dead cells is fairly high, possibly as a result of the dissociation method used to count the cells, it is possible that restricted cell loss due to ethacrynate or cisplatin-induced cytotoxicity may be masked by the overall cell death. We cannot therefore state that cisplatin and ethacrynate are not cytotoxic in our model, but if a part of the inhibition of the IP responses is owed to cytotoxicity, this part would be very small and would appear when these toxins are used at high concentrations.

\section{Putative target proteins}

An obvious proposal could be that the inhibition of the IP signalling pathway is actually a common aspect of various toxic processes mediated by mercuric chloride, ethacrynate, cisplatin and ncomycin since the paired combinations of drugs are additive, apart from both ethacrynate $/ \mathrm{HgCl}_{2}$ and neomycin/cisplatin associations. However one cannot conclude that all these substances exactly interact with the same molecular target. Conversely, since the tested ototoxic molecules are not structurally related, several proteins and/or lipids are probably involved in interaction between the polyphosphoinositide transduction system and the toxic compounds. An indication in favour of such a diversity may be found in the shapes of the inhibition curves (Figs. 1, 2 and 3). Indeed, the slopes of these curves are much steeper in the case of ethacrynate and cisplatin than in the case of mercuric chloride. This suggests that both ethacrynate and cisplatin have a similar effect on the carbachol-stimulated transduction system and mercuric chloride may be acting at several molecular locations.

In the cochlea, the carbachol-triggered IP synthesis presumably involves a number of different proteins each or all of which may be sensitive to acute application of the toxic agents. The first proteins to be activated are the muscarinic receptors. The second ones may be the $G$ proteins (guanine nucleotide binding proteins), of which the $G_{0}, G_{i}$ and $G_{s}$ types have been identified in the organ of Corti (Canlon et al., 1991; Koch and Gloddek, 1991). $G_{0}$ and $G_{1}$ have been shown to interact in vitro with muscarinic receptors (Florio and Sternweis, 1985; Haga et al., 1986). Finally, the activity of phospholipase $\mathrm{C}$ that catalyses the hydrolysis of $\mathrm{PIP}_{2}$ may also be reduced by the ototoxic substances such as aminoglycosides (Hostetler and Hall, 1982).

\section{The case of the aminoglycosides}

Unlike the other drugs, some aspects of the molecular mechanism of the ototoxicity by the aminoglycosides are now well established (Schacht, 1986; Williams et al., 1987). This mechanism includes the binding of aminoglycosides with PIP $_{2}$ (Orsulakova et al., 1976; Stockhorst and Schacht, 1977; Schacht, 1979, 1986). This interaction may cause a decrease in the synthesis of IPs, in the cochlea, as suggested by the in vitro neomycin-mediated inhibition of brain $\mathrm{PIP}_{2}$ hydrolysis by cochlear homogenates (Orsulakova et al., 1976).

In the present report, however, the relative lack of effect of aminoglycosides on the carbachol-enhanced 
IPs formation seems to be controversial with respect to the results reported by Orsulakova et al. (1976) where an inhibition of the $\mathrm{PIP}_{2}$ hydrolysis was obtained by neomycin at a concentration of $0.5 \mathrm{mM}$, a concentration less than the ones we used. The difference between the results of Orsulakova et al. (1976) and ours may be partially explained by differences in the experimental models that could lead to variations in the sensitivity of the assays. For instance, we used whole, developing rat cochleas labelled with tritiated inositol, to measure the effects of ototoxic agents on the synthesis of IPs within the cochlea, whereas Orsulakova et al. examined the effects of neomycin on the hydrolysis of brain derived ${ }^{32} \mathrm{P}$-labelled $\mathrm{PIP}_{2}$ by homogenates of organs of Corti dissected from adult guinea pigs. Comparison of the results obtained with such different systems is difficult. However, one explanation could be that the duration of the neomycin exposure is not long enough to allow an appropriate penetration of the aminoglycoside into the target cells (Schacht, personal communication), hence this would not provide with an efficient neomycin-PIP 2 binding (Schacht, 1986).

Alternately, a possible cause for the absence of effect of aminoglycoside may be sought in the fact that aminoglycosides must be metabolised by enzymes, similar to the ones found in the liver by Huang and Schacht (1990), in order to fully express their ototoxicity. Our in vitro assays may not provide with the physiological conditions necessary for the metabolism of the aminoglycosides.

Takada and Schacht (1982) have shown that an increase in extracellular calcium can reverse the suppression of the cochlear microphonics by acute perfusion of gentamicin. Furthermore, taurine, an amino acid that decreases the calcium availability or sensitivity (Huxtable, 1992), has been reported to potentiate the effects of neomycin (Kay and Davies, 1990). Therefore, the possibility that the relative inefficiency of aminoglycosides may be due to competition with calcium was assessed by depriving the medium of calcium (Fig 4). As no increase in the rate of inhibition was obtained in these conditions, calcium antagonism seems not to be involved here. It is likely that a 20 -fold higher concentration of neomycin $(30 \mathrm{mM}$ neomycin $/ 1.5 \mathrm{mM}$ calcium) is large enough to efficiently displace the calcium from the membrane.

Finally, the demonstrations that aminoglycosides can (1) modulate the GTPase activities in the human platelet membrane (Herrmann and Jakobs, 1988), (2) inhibit the lysosomal phospholipase $\mathrm{C}$ (Hostetler and Hall, 1982) in rat liver, (3) block the agonist stimulated turnover of IPs and protein kinase $\mathrm{C}$ translocation in renal cells (Ramsammy et al., 1988), indicate that aminoglycosides may not exclusively interact with polyphosphoinositides but also with the proteins of the phosphoinositide signalling pathway.

\section{The possible involvement of reactive $\mathrm{SH}$ groups}

When attempting to ascribe some putative molecular targets to the non-aminoglycoside ototoxic drugs, one can speculate that cisplatin and ethacrynate may block the $G$ proteins coupled to phospholipase $C$. This is based on the finding that both these ototoxic substances inhibit the $G$ proteins associated with adenylate cyclases in the guinea-pig cochlea (Koch and Gloddek, 1991). In addition, ethacrynate-induced nephrotoxicity appears to involve an alkylating step (Koechel et al., 1984). Such a mechanism may also exist in ototoxicity. If this is proved to be true, the alkylated SH proteins would be some proteins of the transduction system, including the muscarinic receptors and $G$ proteins. Indeed, $\mathrm{SH}$ groups play a critical role in the regulation of the muscarinic receptors (Aronstam et al., 1978; Hedlund and Bartfai, 1979) and G proteins have three cysteines the alkylation of which decreases $\mathrm{G}$ protein activity (Winslow et al., 1987). Interaction with key SH groups may account for the effects of mercuric chloride too, since this compound is a wellknown SH reagent (Vallee and Ulmer, 1972). In addition, application of other alkylating substances, $\mathrm{N}$-ethylmaleimide and cadmium chloride, have been demonstrated to block the carbachol-elicited IPs synthesis in the rat cochlea (Bartolami et al., 1992a,b). Finally, the possibility that cisplatin and the aminoglycosides may also interact with SH groups cannot be excluded since the reduced glutathione protects against the nephrotoxicity of cisplatin (Zunino et al., 1989) and also decreases the rate of OHCs death elicited by the cytotoxic metabolite of gentamicin (Garetz and Schacht, 1992).

\section{Conclusion}

Altogether, the data presented indicate that the various different ototoxic molecules can reduce the level of IPs synthesis enhanced by an analog of the main efferent neurotransmitter, acetylcholine. In addition, some of the ototoxic drugs can affect this metabolism in an additive way in the 12-day-old rat cochlea. In view of the relatively high concentrations of ethacrynate that are required to block the carbacholstimulated synthesis of IPs, it is unlikely that this is a mechanism contributing to the known ototoxicity of this drug observed in vivo, and the effects induced by both ethacrynate and mercuric chloride on the stria vascularis are more likely to be of greater importance.

\section{Acknowledgements}

Many thanks are due to Drs Michel Eybalin and Guy Richardson for their critical reading of the 
manuscript and to Prof. Jochen Schacht for his useful comments. We are grateful to Pierre Sibleyras for the skilful printing of the figures. S.B. is supported by a grant from the Ministère de la Recherche et de la Technologie.

\section{References}

Altschuler, R.A., Kachar, B., Rubio, J., Parakkal, M. and Fex, J. (1985) Immunocytochemical localization of choline acetyltransferase-like immunoreactivity in the guinea pig cochlea. Brain Res. $338,1-11$.

Anniko, M. and Sarkady, L. (1978) Cochlear pathology following exposure to mercury. Acta Otolaryngol. 85, 213-224.

Aronstam, R.S., Abood, L.B. and Hoss, W. (1978) Influence of sulfhydryl reagents and heavy metals on the functional state of the muscarinic acethylcholine receptor in the rat brain. Mol. Pharmacol. 14, 575-586.

Barron, S.E. and Daigneault, E.A. (1987) Effect of cisplatin on hair cell morphology and lateral wall $\mathrm{Na}$, K-ATPase activity. Hear. Res. 26, 131-137.

Bartolami, S., Guiramand, J., Lenoir, M., Pujol, R. and Récasens, M. (1990) Carbachol-induced inositol phosphate formation during rat cochlea development. Hear. Res. 47, 229-234.

Bartolami, S., Planche, M., Puel, J.L. and Pujol, R. (1992a) Inhibition de la synthèse des inositols phosphates couplée à l'activation des récepteurs muscariniques cochléaires par des agents ototoxiques et alkylants. Abstr. Soc. Neurosci. (Strasbourg, France) 1, A 10 .

Bartolami, S., Planche, M. and Pujol, R. (1992b) Effects of SH-reagents on the cochlear inositol phosphates metabolism and on its blockage by ototoxic drugs. Abstr. Inner Ear Biol. Workshop (Engelberg, Switzerland) 29, 79.

Berridge, M.J., Downes, C.P. and Hanley, M.R. (1982) Lithium amplifies agonist-dependent phosphatidylinositol responses in brain and salivary glands. Biochem. J. 206, 587-595.

Berridge, M.J. and Irvine, R.F. (1984) Inositol phosphate, a novel second messenger in cellular signal transduction. Nature 312 , 315-321.

Canlon, B., Homburger, V. and Bockaert, J. (1991) The identification and localization of the guanine nucleotide binding protein $G_{o}$ in the auditory system. Eur. J. Neurosci. 3, 1338-1342.

Cole, K.S. and Robertson, D. (1992) Early efferent innervation of the developing rat cochlea studied with a carbocyanine dye. Brain Res. 575, 223-230.

Dannhof, B., Roth, B. and Bruns, V. (1991) Anatomical mapping of choline acetyltransferase (ChAT)-like and glutamate decarboxylase (GAD)-like immunoreactivity in outer hair cell efferents in adult rats. Cell Tissue Res. 266, 89-95.

Dulon, D., Zajic, G., Aran, J.M. and Schacht, J. (1989) Aminoglycoside antibiotics impair calcium entry but not viability and motility in isolated outer cochlear hair cells. J. Neurosci. Res. 24, 338-346.

Eybalin, M. and Pujol, R. (1987) Choline acetyltransferase (ChAT) immunoelectron microscopy distinguishes at least three types of efferent synapses in the organ of Corti. Exp. Brain Res. 65, 261-270.

Falk, S.A., Klein, R., Haseman, J.K., Sanders, G.M. and Talley, F.A. (1974) Acute methyl mercury intoxication and ototoxicity in guinea pigs. Arch. Pathol. 97, 297-305.

Florio, V.A. and Sternweis, P.C. (1985) Reconstitution of resolved muscarinic cholinergic receptors with purified GTP-binding proteins. J. Biol. Chem. 260, 3477-3483.

Forge, A. (1985) Outer hair cell loss and supporting cell expansion following chronic gentamicin treatment. Hear. Res. 19, 171-182.

Garetz, S.L. and Schacht, J. (1992) Sulfhydryl compounds reduce gentamicin-induced outer hair cell damage in vitro. Abstr. Assoc Res. Otolaryngol. 15, 328.

Guiramand, J., Lenoir, M., Pujol. R. and Récasens, M. (1990a) Ototoxic and nephrotoxic drugs inhibit agonist-induced inositol phosphate formation in the rat hrain synaptoneurosomes. Toxicol. Lett. 51, 331-338.

Guiramand, J., Mayat, E., Bartolami, S., Lenoir, M., Rumigny, J.F., Pujol, R. and Recasens, M. (1990b) A M3 muscarinic receptor coupled to inositol phosphate formation in the rat cochlea? Biochem. Pharmacol. 39, 1913-1919.

Haga, K., Haga, T. and Ichiyama, A. (1986) Reconstitution of the muscarinic acetylcholine receptor. Guanine nucleotide-sensitive high affinity binding of agonists to purified muscarinic receptors reconstituted with GTP-binding proteins $\left(G_{i}\right.$ and $\left.G_{0}\right)$. J. Biol. Chem. 261, 10133-10140.

Hayashida, T., Hiel, H., Dulon, D, Erre, J.P., Guilhaume, A. and Aran J.M. (1989) Dynamic changes following combined treatment with gentamicin and ethacrynic acid with and without acoustic stimulation. Acta Otolaryngol. 108, 404-413.

Hawkins, J.E., Jr. (1976) Drug ototoxicity. In: Handbook of Sensory Physiology. Vol. V: Auditory System. W.D. Keidel and W.D. Neff, eds. Springer-Verlag, Berlin, Heidelberg, pp. 707-748.

Hedlund, B. and Bartfai, T. (1979) The importance of thiol-and disulfide groups in agonist and antagonist binding to the muscarinic receptor. Mol. Pharmacol. 15, 531-544.

Herrmann, E. and Jackobs, K.H. (1988) Stimulation and inhibition of human platelet membrane high-affinity GTPase by neomycin. FEBS Lett. 229, 49-53.

Hostetler, K.Y. and Hall, L.B. (1982) Aminoglycoside antibiotics inhibit lysosomal phospholipase $\mathrm{A}$ and $\mathrm{C}$ from rat liver in vitro. Bioch. Biophys. Acta 710, 506-509.

Huang, M.Y. and Schacht, J. (1989) Drud-induced ototoxicity. Pathogenesis and prevention. Med. Toxicol. Adverse Drug Exp. 4 , $452-467$.

Huang M Y and Schacht J. (1990) Formation of a cytotoxic metabolite from gentamicin by liver. Biochem Pharmacol. 40, R11-R14.

Huxtable, R.J. (1992) Physiological actions of taurine. Physiol. Rev. $72,101-163$.

Kay, I.S. and Davies, W.E. (1990) The effect of taurine supplementation on the ototoxicity of neomycin in guinea pigs. Eur. Arch Otorhinolaryngol. 247, 37-39.

Koch, T. and Gloddek, B. (1991) Inhibition of adenylate-cyclase-coupled $\mathrm{G}$ protein complex by ototoxic diuretics and cis-platinum in the inner ear of the guinea pig. Eur. Arch. Otorhinolaryngol. 248, $459-464$.

Koechel, D.A., Budd, G.C. and Bretz, N.S. (1984) Acute effects of alkylating agents on canine renal function and ultrastructurc: High-dose ethacrynic acid vs dihydroethacrynic acid and tricrynafen. J. Pharmacol. Exp. Ther. 228, 799-809.

Konishi, T. (1979) Effects of local application of ototoxic antibiotics on cochlear potentials in guinea pigs. Acta Otolaryngol. 88 , $41-46$

Konishi, T. and Hamrick, P.E. (1979) The uptake of methyl mercury in guinea pig cochlea in relation to its ototoxic effect. Acta Otolaryngol. 88, 203-210.

Konishi, T., Gupta, B.N. and Prazma, J. (1983) Ototoxicity of cis-dichlorodiammine platinum (II) in guinea pigs. Am. J. Otolaryngol $4,18-26$.

Kössl, M., Richardson, G.P. and Russell, I.J. (1990) Stereocilia bundle stiffness: Effects of neomycin sulfate, A23187 and concanavalin A. Hear. Res. 44, 217-230.

Kroese, A.B.A., Das, A. and Hudspeth, A.J. (1989) Blockage of the transduction channels of the hair cells in the bullfrog's sacculus by aminoglycoside antibiotics. Hear. Res. $37,203-218$.

Laurell, G. and Engström, B. (1989) The combined effect of cisplatin and furosemide on hearing function in guinea pigs. Hear. Res. 38, $19-26$. 
Laurell, G. and Bagger-Sjöbäck, D. (1991) Degeneration of the organ of Corti following intravenous administration of cisplatin. Acta Otolaryngol. 111, 891-898.

Lenoir, M., Shnerson, A. and Pujol, R. (1980) Cochlear receptor development in the rat with emphasis on synaptogenesis. Anat. Embryol. 160, 253-262.

Lenoir, M. and Puel, J.L. (1987) Dose dependent changes in the rat cochlea following aminoglycoside intoxication. II. Histological study. Hear. Res. 26, 199-209.

Lodhi, S., Weiner, N.D. and Schacht J. (1976) Interactions of neomycin and calcium in synaptosomal membranes and polyphosphoinositide monolayers. Bioch. Biophys. Acta 426, 781-785.

McAlpine, D. and Johnstone, B.M. (1990) The ototoxic mechanism of cisplatin. Hear. Res. 47, 191-204.

Nakai, Y., Konishi, K., Chang, K.C., Ohashi, K., Morisaki, N., Minowa, Y. and Morimoto, A. (1982) Ototoxicity of the anticancer drug cisplatin. An experimental study. Acta Otolaryngol. 93, 227-232.

Niedzielski, A., Ono, T. and Schacht, J. (1992) Cholinergic regulation of the phosphoinositide second messenger system in the guinea pig organ of Corti. Hear. Res. 59, 250-254.

Nishizuka, Y. (1984) Turnover of inositol phospholipids and signal transduction. Science 225, 1365-1370.

Nuttall, A.L., Marques, D.M. and Lawrence, M. (1977) Effects of perilymphatic perfusion with neomycin on the cochlear microphonic potential in the guinea pig. Acta Otolaryngol. 83, 393-400.

Orsulakova, A., Stockhorst, E. and Schacht, J. (1976) Effect of neomycin on phosphoinositides labelling and calcium binding in guinea-pig inner ear tissues in vivo and in vitro. J. Neurochem. 26, 285-290.

Pujol, R. (1986) Periods of sensitivity to antibiotic treatment. Acta Otolaryngol. Suppl. 429, 29-33.

Ramsammy L.S., Josepovitz C. and Kaloyanides G.J. (1988) Gentamicin inhibits agonist stimulation of the phosphatidylinositol cascade in primary cultures of rabbit proximal tubular cells and in rat renal cortex. J. Pharmacol. Exp. Ther. 247, 989-996.

Richardson, G.P., Russell, I.J., Wasserkort, R. and Hans, M. (1989) Aminoglycoside antibiotics and lectins caused irreversible increases in the stiffness of cochlear hair-cell stereocilia. In: J.P. Wilson and D.T. Kemp (Eds.), Cochlear Mechanisms - Structure, Function and Models, Plenum Press, New York, pp. 57-65.

Richardson, G.P. and Russell, I.J. (1991) Cochlear cultures as a model system for studying aminoglycoside induced ototoxicity. Hear. Res. 53, 293-311.

Russell, N.J., Fox, K.E. and Brummett, R.E. (1979) Ototoxic effects of the interaction between kanamycin and ethacrynic acid.
Cochlear ultrastructure correlated with cochlear potentials and kanamycin levels. Acta Otolaryngol. 88, 369-381.

Rybak, L.P. (1986) Ototoxic mechanisms. In: R.A. Altschuler, D.W. Hoffman and R.P. Bobbin (Eds.), Neurobiology of Hearing: The Cochlea. Raven Press, New York. pp. 441-454

Saito, T., Moataz, R. and Dulon, D. (1991) Cisplatin blocks depolarization-induced calcium entry in isolated cochlear outer hair cells. Hear. Res. 56, 143-147.

Schacht, J. (1979) Isolation of an aminoglycoside receptor from guinea pig inner ear tissues and kidney. Arch. Oto-Rhino-Laryngol. 224, 129-134.

Schacht, J. (1986) Molecular mechanisms of drug-induced hearing loss. Hear. Res. 22, 297-304.

Schacht, J. and Zenner, H.P. (1987) Evidence that phosphoinositides mediate motility in cochlear outer hair cells. Hear. Res. 31, 155-160.

Simmons, D.D., Manson-Gieseke, L., Hendrix, T.W. and McCarter, $S$. (1990) Reconstructions of efferent fibers in the postnatal hamster cochlea. Hear. Res. 49, 127-140.

Stockhorst, E. and Schacht, J. (1977) Radioactive labeling of phospholipids and proteins by cochlear perfusion in the guinea pig and the effect of neomycin. Acta Otolaryngol. 83, 401-409.

Takada, A. and Schacht, J. (1982) Calcium antagonism and reversibility of gentamicin-induced loss of cochlear microphonics in the guinea pig. Hear. Res. 8, 179-186.

Thalmann, R., Ise, I., Bohne, B.A. and Thalmann, I. (1977) Actions of 'loop' diuretics and mercurials upon the cochlea. Acta Otolaryngol. 83, 221-232.

Vallee, B.L. and Ulmer, D.D. (1972) Biochemical effects of mercury, cadmium, and lead. Ann. Rev. Biochem. 41, 91-129.

Wang, B.M., Weiner, N.D., Takada, A. and Schacht, J. (1984) Characterization of aminoglycoside-lipid interactions and development of a refined model for ototoxicity testing. Biochem. Pharmacol. 33, 3257-3262.

Williams, S.E., Zenner, H.P. and Schacht, J. (1987) Three molecular steps of aminoglycoside ototoxicity demonstrated in outer hair cells. Hear. Res. 30, 11-18.

Winslow, J.W., Bradley, J.D., Smith, J.A. and Neer, E.J. (1987) Reactive sulfhydryl groups of alpha 39 , a guanine nucleotide binding protein from brain. Function and location. J. Biol. Chem. 262, 4501-4507.

Zunino, F., Pratesi, G., Micheloni, A., Cavalletti, E., Sala, F. and Tofanetti, O. (1989) Protective effect of reduced glutathione against cisplatin-induced renal and systematic toxicity and its influence on the therapeutic activity of the antitumor drug. Chem. Biol. Interact, 70, 89-101. 